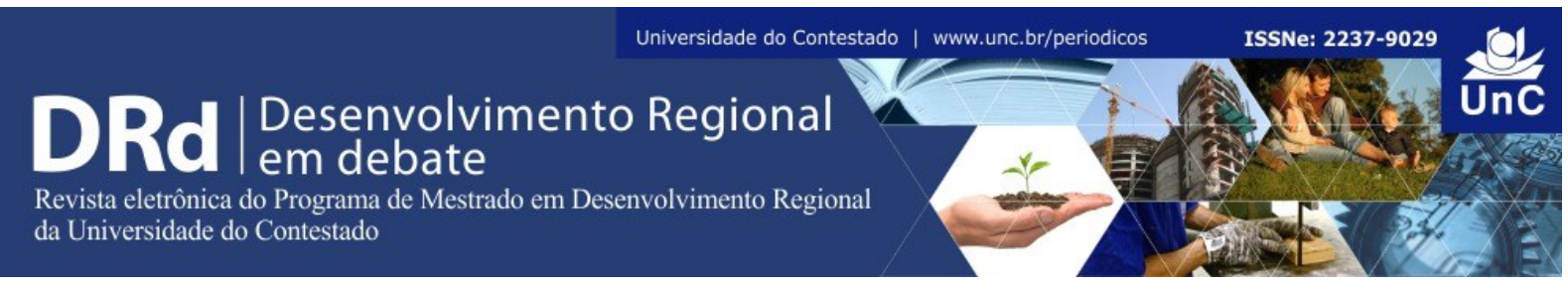

\title{
TIPIFICAÇÃO DE PROPRIEDADES LEITEIRAS ADMINISTRADAS POR JOVENS AGRICULTORES NA REGIÃO DO PLANALTO NORTE CATARINENSE
}

\author{
Marlon Dutra ${ }^{1}$ \\ Lauro William Petrentchuk ${ }^{2}$ \\ João Paulo Pereira Paes ${ }^{3}$
}

\begin{abstract}
RESUMO
O desenvolvimento e a aplicação de indicadores de sustentabilidade que auxiliem na tomada de decisões na pecuária leiteira é uma importante demanda atual. No Planalto Norte Catarinense a pecuária leiteira tem crescido por meio do apoio de entidades públicas, privadas e organizações de agricultores. Esse crescimento tem suscitado discussões sobre modelos produtivos locais, especialmente no público jovem, que tem uma maior expectativa de vida produtiva. Esse trabalho tem como objetivo tipificar as unidades produtoras de leite no Planalto Norte Catarinense com base nas características produtivas como ferramenta para explicar a eficiência da atividade. Foram aplicados questionários em julho de 2018 em 26 propriedades rurais onde os jovens são protagonistas. A tipificação das propriedades rurais ocorreu em função de dez variáveis. Os resultados indicam maior influência da geração de renda por área na atividade leiteira em comparação aos custos operacionais. Nesses dois eixos, as propriedades foram divididas em cinco grupos: alta eficiência produtiva; alta produtividade animal; alto custo operacional; baixa eficiência produtiva; intermediário. Os indicadores utilizados se mostraram eficientes para retratar a realidade da atividade leiteira e os resultados sugerem que para maior lucratividade na atividade leiteira, é necessário gerir bem a lotação animal, a produtividade animal e os custos operacionais.
\end{abstract}

Palavras-chave: Indicadores. Pecuária leiteira. Sustentabilidade. Sucessão rural. Tipificação.

\footnotetext{
${ }^{1}$ Especialista em Desenvolvimento Rural Sustentável. Empresa de Pesquisa Agropecuária e Extensão Rural de Santa Catarina (EPAGRI). Canoinhas, Santa Catarina. E-mail: marlondutra@epagri.sc.gov.br ORCID: https://orcid.org/0000-0001-9241-8153

${ }^{2}$ Mestre em Desenvolvimento Regional. Instituto Federal de Educação, Ciência e Tecnologia de Santa Catarina (IFSC). Canoinhas, Santa Catarina. Brasil. E-mail: lauro.william@ifsc.edu.br. ORCID: https://orcid.org/00000002-7570-8770IFSC

${ }^{3}$ Doutor em Proteção de Plantas. Instituto Federal de Educação, Ciência e Tecnologia de Santa Catarina (IFSC). Canoinhas, Santa Catarina. Brasil. E-mail: joao.paes@ifsc.edu.br. ORCID: https://orcid.org/0000-0002-36511166.
}

DRd - Desenvolvimento Regional em debate (ISSNe 2237-9029)

v. 9 , p. 387-401, 2019. 


\title{
TYPIFICATION OF FARMS ADMINISTERED BY YOUNG FARMERS IN THE REGION OF THE NORTH CATARINENSE PLATEAU
}

\begin{abstract}
The development and application of sustainability indicators that assist in decision making in dairy farming is an important current demand. In the Planalto Norte Catarinense dairy farming has grown through the support of public and private entities and farmers' organizations. This growth has led to discussions about local productive models, especially among young people, who have a longer productive life expectancy. This work aims to typify the milk production units in the Planalto Norte Catarinense based on the productive characteristics as a tool to explain the efficiency of the activity. Questionnaires were applied in July 2018 on 26 rural properties where young people are protagonists. The typification of rural properties occurred as a function of ten variables. The results indicate a greater influence of the income generation by area in the dairy activity compared to the operational costs. In these two axes, the properties were divided into five groups: high productive efficiency; high animal productivity; high operating cost; low productive efficiency; intermediary. The indicators used were efficient to portray the reality of the milk activity and the results suggest that for greater profitability in milk production, it is necessary to manage well the animal stocking, the animal productivity and the operational costs.
\end{abstract}

Keywords: Indicators. Dairy produtction. Sustainability. Farm succession. Typification.

\section{INTRODUÇÃO}

A intensificação da pecuária nos últimos 20 anos levantou diversas questões sobre segurança alimentar e impactos ambientais; sendo, a viabilidade desses sistemas questionada a longo prazo, devido às crises com doenças de animais, efeitos negativos sobre a renda agrícola, o bem-estar animal e o meio ambiente, despertando o interesse por sistemas pecuários sustentáveis, que sejam economicamente viáveis, socialmente aceitáveis, ambientalmente corretos, que busquem o bem-estar animal, e que possam ser mensurados e os dados generalizados (CALKER et al., 2005; LEBACQ et al., 2013).

Essa conjuntura levou a busca de indicadores de sustentabilidade a nível regional, de propriedade ou de atividade agrícola; e isso tem gerado um importante questionamento; quais os indicadores mais apropriados para avaliar a sustentabilidade dos sistemas produtivos? (BOCKSTALLER et al., 2008).

Poucos estudos abordam a respeito da seleção de indicadores, por isso não há consenso sobre uma lista de indicadores, sendo que muitos estudos se concentram na análise de apenas um eixo, principalmente sobre os impactos ambientais (LEBACQ et al., 2013).

A produção de leite tem uma importância econômica, social e ambiental própria. A renda é mensal, diferente de outras atividades agropecuárias; tem importância social muito evidente na família e nas relações com a comunidade devido à rotina na propriedade, e ambientalmente tem um grande uso dos recursos naturais, sendo uma atividade extremamente 
complexa, favorecendo a busca por indicadores como medida de eficiência (VILELA et al., 2002).

Em Santa Catarina, a Epagri tem realizado acompanhamento de propriedades rurais e tem destacado indicadores para o sistema a base de pastagens como capacidade de suporte; produtividade animal, produtividade por área, qualidade do leite, bem-estar dos animais, incremento de renda para o produtor e por área (CORDOVA et al., 2012; FAO/EPAGRI, 2018).

Existe um contexto global que busca a sustentabilidade para a atividade pecuária por meio de modelos produtivos sustentáveis, e os jovens são o público que mais pode se beneficiar com essa construção, devido à longa vida ativa de trabalho. Com a Política Nacional da Juventude, fica definido que jovens são classificados por faixa etária que compreende entre 15 e 29 anos (NOVAES et al., 2006).

A pecuária é uma atividade importante em Santa Catarina, principalmente a produção de leite. No Estado, 28 \% da área agrícola é ocupada por pastagens; são produzidos 3.214 .754 litros de leite por ano, gerando uma receita de R \$ 3.575.207,00 em 89.043 estabelecimentos rurais, e o leite é a terceira atividade que mais gera valor, perdendo apenas para a produção de suínos e aves (EPAGRI/CEPA, 2017; IBGE, 2017). Isso coloca o Estado como quarto produtor de leite do país, atrás de Minas Gerais, Rio Grande do Sul e Paraná. (EPAGRI/CEPA, 2017).

O Planalto Norte Catarinense é uma região localizada ao norte de Santa Catarina, abrangendo treze municípios: Bela Vista do Toldo, Campo Alegre, Canoinhas, Irineópolis, Itaiópolis, Mafra, Major Vieira, Monte Castelo, Papanduva, Porto União, Rio Negrinho, São Bento do Sul e Três Barras.

No Planalto Norte Catarinense (P.N.C.), a atividade leiteira também tem aumentado significativamente a sua expressão, principalmente nas pequenas propriedades (HANISCH et al., 2006), devido a pressão que a fumicultura vem sofrendo, a conscientização da diversificação das atividades rurais e a organização dos produtores que vem se fortalecendo (HANISCH et al., 2016; SUDOSKI, 2016; SILVA, 2017).

Segundo dados da Epagri/Cepa e IBGE, em 2017 a região produziu 2,9 \% do leite no Estado, que é equivalente a 81,2 milhões de litros de leite por ano em 1.182 estabelecimentos rurais declarados que produziram leite, com as maiores produções em Mafra, Canoinhas e Porto União. Durante o período de 2011 a 2015, houve aumento de $61,1 \%$ na produção regional, colocando a Região na segunda posição entre as regiões que mais expandiram sua produção no Estado (EPAGRI/CEPA, 2017).

Porém, apenas 4\% dos estabelecimentos agropecuários de Santa Catarina são gerenciados por jovens (IBGE, 2017). Esse baixo número de jovens gerenciando propriedades mostra que existem poucos jovens no campo, e/ou que a atividade leiteira não é atrativa para os mesmos, e/ou que muitos jovens são usados como mão de obra pelos pais.

Com essa conjuntura apresentada, e a busca pelo desenvolvimento sustentável, decidiuse com este trabalho apoiar a atividade leiteira, e tipificar as Unidades Produtoras de Leite na região do Planalto Norte Catarinense com base nas características produtivas como ferramenta para explicar a eficiência produtiva. 


\section{MATERIAL E MÉTODOS}

Este trabalho caracteriza-se como pesquisa aplicada e foi realizado por meio do emprego de questionários fechados com perguntas quantitativas para tipologia das propriedades rurais onde os jovens são protagonistas na atividade rural.

A Epagri desenvolve um trabalho de extensão com o público jovem de Santa Catarina desde o ano de 2013, oferecendo cursos de capacitação e liderança com duração de oito meses.

Esta pesquisa foi realizada no mês de julho de 2018 em 26 propriedades rurais com jovens entre 17 e 29 anos, que participaram do curso de capacitação e liderança, e que são assistidos pela Epagri há um período de no mínimo de 06 meses.

A pesquisa englobou os municípios de Canoinhas, Bela Vista do Toldo, Monte Castelo, Mafra, Itaiópolis e Rio Negrinho. Os questionários foram distribuídos aos jovens para que pudessem refletir sobre a atividade leiteira em sua propriedade, e responder com veracidade todas as informações. Os jovens ficaram com os questionários por quatro dias para preenchimento.

Dos 26 questionários aplicados, nove foram retirados da análise por entender que havia uma grande falta de informações e estes não poderiam participar da amostra para análise estatística. Todos os dados coletados foram organizados em um banco de dados consolidado por meio da utilização de planilha eletrônica do software Excel 2013.

Para análise estatística utilizou-se o teste estatístico de Análise de Componentes Principais (PCA), fragmentando as propriedades rurais em grupos de similaridade, formando categorias (tipologia das propriedades) com base nas variáveis que tiveram maior influência.

Para análise de componentes principais foram utilizadas dez variáveis escolhidas devido a quatro fatores fundamentais que elas apresentam:

1 - Fidelidade dos dados: Em geral, quesitos econômicos como produção de leite, receita e custos com ração foram preenchidos adequadamente.

2 - Representatividade econômica, social e ambiental: As variáveis utilizadas representam os fatores econômicos mais importantes para a atividade leiteira, bem como fatores sociais pelo uso de mão de obra e ambientais pelo uso da terra, gerando uma forte representatividade.

3 - Capacidade de generalização: As variáveis utilizadas são fáceis de medir, pois em qualquer propriedade é possível calcular esses fatores, e replicar essa análise.

4 - Experiência dos autores: Com o objetivo de encontrar as variáveis que mais afetam as propriedades rurais, selecionaram-se as consideradas mais importantes, para evitar gerar muita complexidade nos resultados e esconder efeitos importantes para tipificação (TABACHNICK; FIDELL, 2007; MAYER, 2017).

As variáveis utilizadas foram as seguintes: 
I - Litros de leite por hectare (litros/leite/ha): É composta pela produção de leite anual dividido pela área utilizada ao longo do ano.

II - Margem bruta por hectare (MB/ha): É composta pela receita bruta anual do leite menos os custos operacionais por ano dividido pela área utilizada.

III - Seguridade Social (Seg/social): Essa variável é composta pela receita bruta anual (receita total do leite - custos operacionais), dividido pelo número de pessoas que trabalham na atividade vezes o salário-mínimo de 2018 vezes 12 meses.

IV - Produtividade por vaca por ano (Prod/vaca/ano): Composta pela produção de leite no ano dividido pelo número de vacas no rebanho.

V - Lucratividade (Lucrat): É composta pela receita total da atividade menos o custo operacional e fixo, dividido pela receita total da atividade multiplicado por 100 .

VI - Número de vacas por hectare (N. vacas/ha): Essa variável é formada pelo número de vacas no rebanho no ano, dividido pela área utilizada pela atividade leiteira no ano.

VII - Eficiência da mão de obra (EF/MO): Essa variável é formada pela produção anual de leite, dividido pelo número de pessoas que efetivamente trabalham na atividade leiteira.

VIII - Custos operacionais (P.C.O): É formado pelo custo operacional anual, dividido pela receita anual do leite multiplicado por 100. Representa a portagem da receita gasta com custos operacionais.

IX - Custos com ração (P.C.R): É formado pelo custo anual com ração, dividido pela receita anual do leite multiplicado por 100. Demonstra a portagem da receita gasta com ração.

$\mathrm{X}$ - Porcentagem de vacas no rebanho (P.vacas.reb): É composta pelo número de vacas na propriedade, dividido pelo número total de animais na propriedade multiplicado por 100 .

Após a análise de componentes principais, verificaram-se as diferenças estatísticas entre os grupos formados e as variáveis estudadas através do valor de $\mathrm{p}$ ( $\mathrm{p}$-value). A matriz utilizada foi a de correlação, construída e analisada pela função PCA, do pacote FactoMineR, do programa R (R CORE TEAM, 2018). 


\section{RESULTADOS E DISCUSSÃO}

Na Tabela 01 é possível verificar o resumo das variáveis quantitativas.

Tabela 01 - Resumo das variáveis quantitativas.

\begin{tabular}{l|l|r|r|r|r}
\hline \multicolumn{1}{c|}{ Variáveis quantitativas } & \multicolumn{1}{c|}{ Unidade } & Mínimo & Mediana & Média & Máximo \\
\hline Número de vacas na propriedade & Cabeças & 8 & 17 & 15,41 & 24 \\
\hline Lucratividade & \% & $-2,86$ & 15,80 & 18,93 & 48,04 \\
\hline Litros de leite por hectare & Leite/hectare & 1111 & 7650 & 7882 & 16667 \\
\hline Número de vacas por hectare & Vacas/hectare & 1,1 & 1,8 & 2,05 & 3,33 \\
\hline Produtividade anual por vaca & Litros/vaca/ano & 800 & 3529 & 3721 & 6316 \\
\hline Custo operacional por ano & R\$/ano & 2000 & 24000 & 33933 & 119476 \\
\hline Custo anual com ração & R\$/ano & 0 & 10000 & 15903 & 53488 \\
\hline Eficiência da mão de obra & Litros de leite/homem/ano & 2667 & 20000 & 20762 & 55000 \\
\hline Margem bruta por hectare & R\$/hectare/ano & 522 & 4333 & 4974 & 14167 \\
\hline Seguridade Social & $\begin{array}{l}\text { Número de vezes que recebe } \\
\text { o salário-mínimo por pessoa }\end{array}$ & 0,15 & 1,15 & 1,207 & 3,56 \\
\hline
\end{tabular}

Fonte: Elaborado pelos autores, 2018.

A partir da análise de componentes principais foi possível inferir que $68,75 \%$ da variação que ocorre nas propriedades podem ser explicadas por duas dimensões (FIGURA 01).

Figura 01 - Efeito e correlação das variáveis na construção dos agrupamentos.

\section{Variables factor map (PCA)}

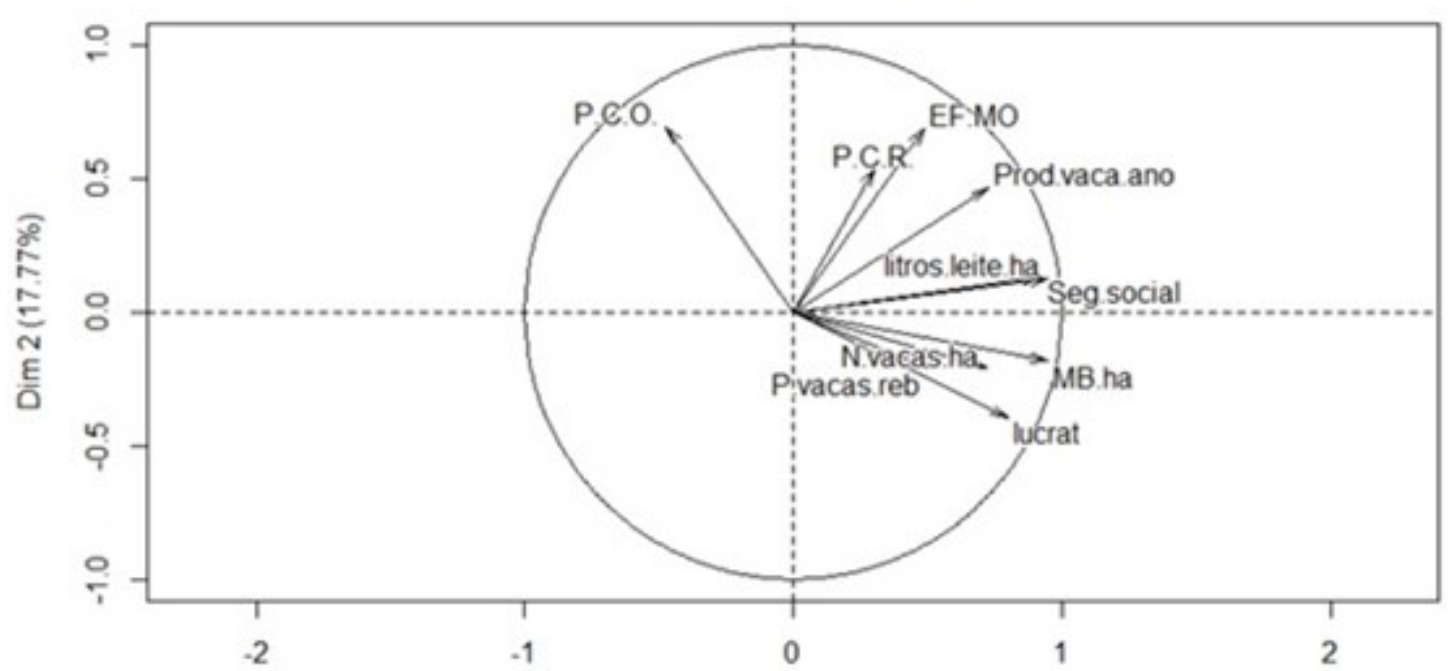

$\operatorname{Dim} 1(51.18 \%)$

Fonte: Elaborado pelos autores, 2018.

As variáveis que mais influenciaram para a formação da dimensão 1, que explicou $51,18 \%$ da variação foram: margem bruta por hectare; litros de leite por hectare; seguridade social e lucratividade. Pelo caráter econômico das variáveis formadoras da dimensão 1, vamos

DRd - Desenvolvimento Regional em debate (ISSNe 2237-9029) 
tratá-la como dimensão geradora de renda por área. Na dimensão 2 que explicou 17,71\% da variação, a porcentagem do custo operacional em função da receita bruta anual e a eficiência da mão de obra foram as variáveis de maior influência. Em função disso, essa dimensão será denominada porcentagem do custo operacional (P.C.O.).

A variável P.C.O. é a única variável vinculada à menor geração de renda por área. Esta variável mostra que propriedades com menor eficiência produtiva, terão seus custos operacionais maiores proporcionalmente à receita.

Na tabela 02 são apresentados detalhadamente a correlação das variáveis formadoras dos eixos de categorização das propriedades rurais analisadas.

Tabela 02 - Variáveis utilizadas pela PCA para formação das dimensões 1 e 2, com sua correlação e valor de p. Variáveis com valores de correlação positivo tem proximidade nos agrupamentos, e variáveis com valores negativos são opostas.

\begin{tabular}{|c|c|c|}
\hline \multicolumn{3}{|c|}{$\begin{array}{c}\text { Correlação das Variáveis Formadoras dos Eixos de Categorização das } \\
\text { Propriedades Rurais }\end{array}$} \\
\hline Dimensão 1 & Correlação & p-value \\
\hline $\begin{array}{l}\text { Margem Bruta por ha } \\
(\mathrm{MB} / \mathrm{ha})\end{array}$ & 0.9471591 & $8.320319 \mathrm{e}-09$ \\
\hline $\begin{array}{l}\text { Litros de Leite por ha } \\
\text { (litros/leite/ha) }\end{array}$ & 0.9452284 & $1.082857 \mathrm{e}-08$ \\
\hline $\begin{array}{l}\text { Seguridade Social } \\
\text { (Seg/social) }\end{array}$ & 0.9210914 & $1.559329 \mathrm{e}-07$ \\
\hline Lucratividade (Lucrat) & 0.7990620 & $1.192243 \mathrm{e}-04$ \\
\hline $\begin{array}{l}\text { Produtividade por vaca no ano } \\
\text { (Prod/vaca/ano) }\end{array}$ & 0.7244811 & $1.004225 \mathrm{e}-03$ \\
\hline $\begin{array}{l}\text { Número de vacas por ha } \\
\text { (N.vacas/ha) }\end{array}$ & 0.7180059 & $1.170630 \mathrm{e}-03$ \\
\hline $\begin{array}{l}\text { Porcentagem de Vacas no Rebanho } \\
\text { (P.vacas.reb) }\end{array}$ & 0.5018182 & $4.012393 \mathrm{e}-02$ \\
\hline $\begin{array}{l}\text { Eficiência da mão de obra } \\
\text { (EF/MO) }\end{array}$ & 0.4850534 & $4.843601 \mathrm{e}-02$ \\
\hline Dimensão 2 & Correlação & p-value \\
\hline $\begin{array}{l}\text { Porcentagem do Custo } \\
\text { Operacional em função da Receita } \\
\text { Bruta Anual } \\
\text { (P.C.O.) }\end{array}$ & 0.6973064 & 0.001861899 \\
\hline $\begin{array}{l}\text { Eficiência da mão de obra } \\
\text { (EF/MO) }\end{array}$ & 0.6897189 & 0.002186913 \\
\hline $\begin{array}{l}\text { Porcentagem do Custo de Ração em } \\
\text { função da } \\
\text { Receita Bruta Anual } \\
\text { (P.C.R.) }\end{array}$ & 0.5366357 & 0.026354990 \\
\hline
\end{tabular}

Fonte: Elaborado pelos autores, 2018.

A partir desses resultados as propriedades entrevistadas foram agregadas em grupos através do método de agrupamentos por Análise de Componentes Principais (PCA), que diferenciou estas propriedades em cinco grupos distintos (Figura 02). 
Tipificação de propriedades leiteiras administradas por jovens agricultores na região do planalto norte catarinense

Figura 02 - Formação de agrupamentos de propriedades leiteiras a partir da análise de variáveis de desempenho produtivo.

\section{Individuals factor map (PCA)}

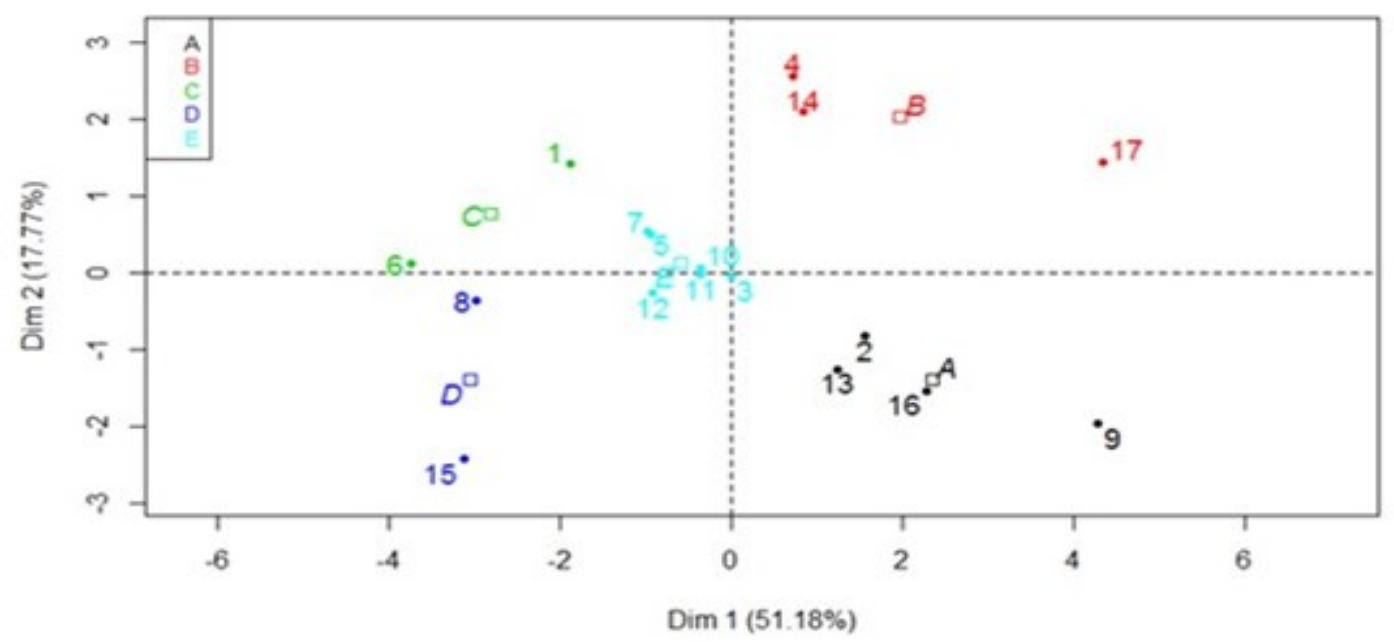

Fonte: Elaborado pelos autores, 2018.

A tabela 03 explica as diferenças entre os cinco grupos formados na PCA. É possível verificar as médias de cada grupo em comparação as variáveis que formam as dimensões $01 \mathrm{e}$ 02 Além das médias de cada variável, também está incluso a identificação por número de cada propriedade que forma o grupo.

Tabela 03 - Categorização pela média de cada grupo em relação às variáveis formadoras da dimensão 1 e 2 , com o número da propriedade que pertence a cada grupo e p-value que indicam a diferença estatística de cada grupo.

\begin{tabular}{|c|c|c|c|c|c|c|}
\hline \multicolumn{7}{|c|}{ Dimensão 1} \\
\hline Grupos & Unidades & A & $\mathrm{B}$ & $\mathrm{C}$ & $\mathrm{D}$ & $\mathrm{E}$ \\
\hline $\mathrm{MB} / \mathrm{ha}$ & $\mathrm{R} \$ /$ ha/ano & 8951,75 & 6828,667 & 1219,5 & 1027 & 3961,167 \\
\hline Litros/leite/ha & Litros/leite/ha/ano & 11165,38 & 11991,43 & 3444,44 & 2355,55 & 6958,33 \\
\hline Seg/social & $\begin{array}{l}\text { Número de vezes que } \\
\text { recebe o salário } \\
\text { mínimo de } 2018 \text { por } \\
\text { mês por pessoa na } \\
\text { atividade }\end{array}$ & 1,82 & 2,123333 & 0,615 & 0,175 & 0,881667 \\
\hline Lucrat & $\%$ & 40,9 & 19,4 & 3,6 & 5,5 & 15,1 \\
\hline Prod/vaca/ano & Litros/leite/vaca/ano & 4013,65 & 5624,43 & 2516,67 & 1400 & 3750,51 \\
\hline N.vacas/ha & Vacas/ha & 2,8 & 2,2 & 1,3 & 1,6 & 1,9 \\
\hline P.vacas.reb & $\%$ & 70,9 & 60,5 & 40,5 & 47,5 & 48,3 \\
\hline $\mathrm{EF} / \mathrm{MO}$ & Litros/leite/pessoa/ano & 18483,33 & 43153,33 & 19250 & 4333,335 & 17064,48 \\
\hline Propriedades & & $2,9,13,16$ & $4,14,17$ & 1,6 & 8,15 & $3,5,7,10,11,12$ \\
\hline p-value & & 0.01572560 & & & 0.04455004 & \\
\hline \multicolumn{7}{|c|}{ Dimensão 2} \\
\hline Grupos & & $\mathrm{A}$ & $\mathrm{B}$ & $\mathrm{C}$ & $\mathrm{D}$ & $\mathrm{E}$ \\
\hline P.C.O. & $\%$ & 31,7425 & 57,46333 & 69,18 & 47,285 & 46,45833 \\
\hline $\mathrm{EF} / \mathrm{MO}$ & Litros/leite/pessoa/ano & 18483,33 & 43153,33 & 19250 & 4333,335 & 17064,48 \\
\hline P.C.R. & $\%$ & 15,9525 & 29,83333 & 10,61 & 3 & 23,80667 \\
\hline Propriedades & & $2,9,13,16$ & $4,14,17$ & 1,6 & 8,15 & $3,5,7,10,11,12$ \\
\hline p-value & & 0.0145057 & 0.0015222 & & & \\
\hline
\end{tabular}

Fonte: Elaborado pelos autores, 2018.

DRd - Desenvolvimento Regional em debate (ISSNe 2237-9029) 
Para melhor compreensão dos resultados, construiu-se a Figura 03, que mostra pela coloração onde cada grupo está localizado, as variáveis que constroem cada eixo, e a linha de tendência que mostra o efeito da eficiência sobre o agrupamento.

Figura 03 - Quadro de eficiência produtiva baseado no mapa de fatores individuais (PCA) com divisão em quatro quadrantes. Formação dos quadrantes segundo a dimensão 01 e a dimensão 02 com linha de tendência da eficiência produtiva.

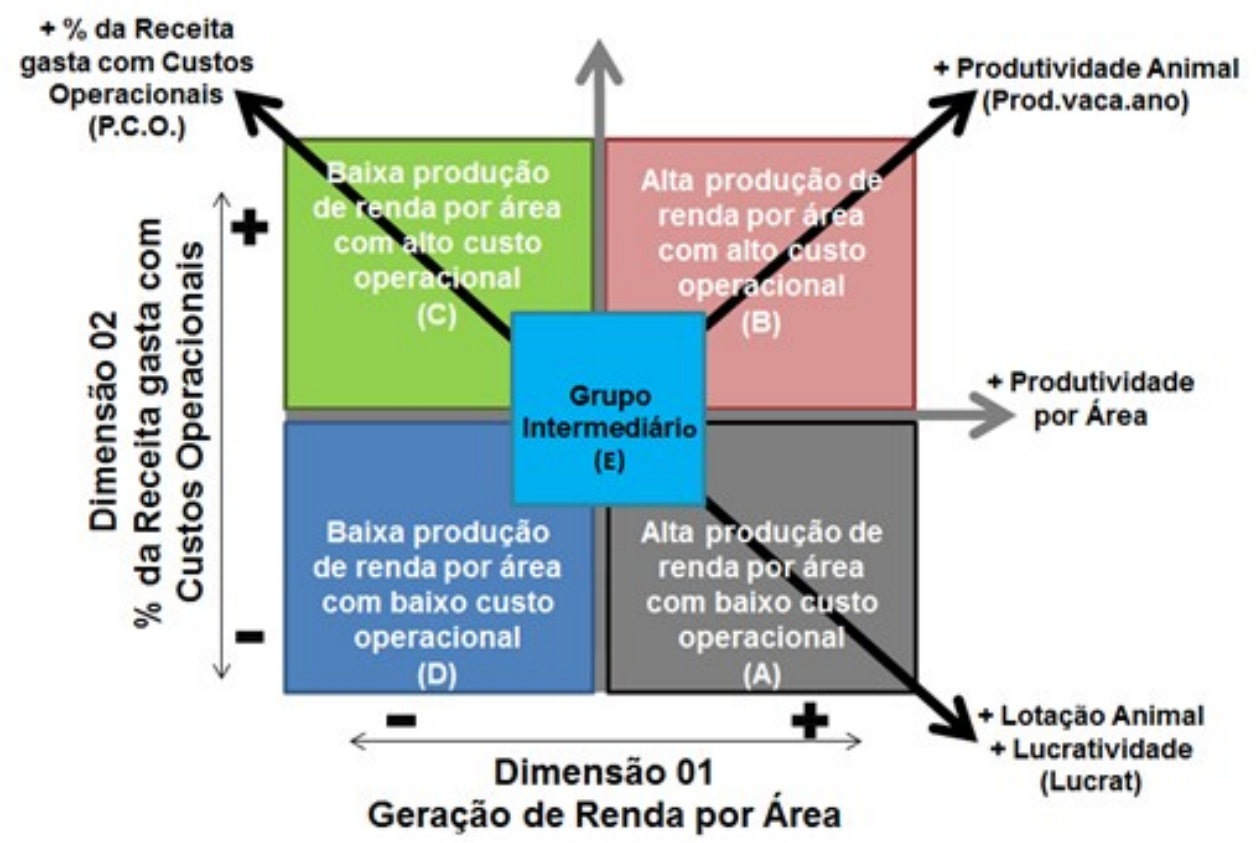

Fonte: Elaborado pelos autores, 2018.

Esses resultados corroboram com resultados observados por Dias (2018), que realizou análise de fatores quali-quantitativos de alimentação e ordenha, e verificou que a produção comparada aos custos com alimentação também são variáveis responsáveis pela formação das duas primeiras dimensões. Ferreira (2016) destaca os custos em alimentação e a mão de obra como as variáveis de maior impacto na atividade leiteira na região de Aquidauana/M.S. De modo geral, a alimentação do rebanho tem sido a variável principal para a produção de leite, e seus custos variam conforme o sistema de produção adotado (GONÇALVES, 2009). Esses trabalhos afirmam como a geração de renda versus os custos operacionais podem afetar o desempenho da atividade leiteira.

A partir dos resultados da PCA, os grupos foram denominados em: Alta Eficiência produtiva (grupo $\mathrm{A}$ ) = Foi o mais eficiente economicamente, devido à margem bruta por hectare e a lucratividade. Além disso, teve a melhor lotação animal (N.vacas/ha e P.vacas.reb), e a menor porcentagem do custo operacional. Dessa forma, geraram maior renda por área com menor custo operacional gerando um círculo de eficiência produtiva, e tornando o grupo modelo a ser seguido pelas propriedades rurais do P.N.C.

Alta Produtividade Animal (grupo B) = Esse grupo tem como fatores mais influentes a produtividade animal, o gasto com ração e a eficiência de mão de obra. O grupo B teve a 
maior produtividade animal geral e a maior eficiência da mão de obra, mas isso não levou a maior lucratividade. Esses fatores mostram que mesmo com uma alta geração de renda por área, os custos operacionais altos (principalmente os gastos com ração), diminuem a lucratividade. A utilização de uma proporção de alimentação maior de pastagens poderia aumentar a lucratividade dessas propriedades. Outro ponto que deve ser destacado é que nem sempre a maior eficiência da mão de obra gera mais lucros, pois o que encontramos nesse grupo é uma grande quantidade de trabalho das pessoas envolvidas, mas não obtiveram as maiores remunerações. Por isso deve-se sempre observar a produtividade baseada na área, utilizando fatores que levam em consideração a produção por área x custos, e não somente a produtividade animal, pois, observar apenas um fator isolado é extremamente tendencioso para aferir eficiência produtiva.

Alto Custo Operacional (grupo $\mathrm{C}$ ) $=\mathrm{O}$ referido grupo teve uma produtividade por área e animal muito baixa comparada aos padrões apresentados nos grupos A e B. Mas o principal fator que o diferencia dos demais é o custo operacional. Proporcionalmente, este grupo é o que mais emprega dinheiro da sua receita no custeio da atividade leiteira. O problema que deve ser superado são os baixos índices produtivos, como a lotação e produtividade animal, pois, mesmo com um investimento alto em custeio, a resposta dada pela atividade leiteira é baixa. É necessário aumentar a eficiência produtiva desse grupo, e provavelmente não existam recursos para investir na atividade. Esse grupo necessita aumentar a produtividade animal (4.000 litros/leite/vaca/ano), melhorar a lotação animal (3 vacas/ha), diminuir o uso de concentrados, e utilizar esses recursos na melhoria do sistema produtivo, pois esses animais não necessitam desse uso de concentrados pela produtividade que apresentam. Seria importante investir em pastagens de alta produção, piqueteamento, colocação de água nos piquetes e inseminação artificial, que dentro de um período de três a cinco anos, essa situação possivelmente seria revertida. Este grupo de propriedades deve ser observado nos municípios pela assistência técnica e extensão rural para que essa situação seja superada.

Baixa eficiência produtiva (grupo $\mathrm{D}$ ) $=\mathrm{O}$ grupo apresentou algumas tendências de baixa eficiência produtiva. Esse grupo se encontra com os mesmos índices produtivos do grupo $\mathrm{C}$, porém, com um custo operacional menor, acaba tendo uma pequena lucratividade. Não houve nenhuma variável que foi capaz de explicar a variabilidade desse grupo de propriedades, mas é importante que esse grupo continue a implantação em pastagens de alta produção, piqueteamento, colocação de água e inseminação artificial. Assim, é provável que em pouco tempo esse grupo transacione para a mesma eficiência produtiva do grupo E.

Intermediário $($ grupo $\mathrm{E})=\mathrm{O}$ grupo está em uma posição intermediária no gráfico. Esse grupo apresenta valores de produção muito próximos à média geral de todas as propriedades. Possui uma geração de renda média por área, produtividade animal média, recebe o valor próximo a um salário-mínimo mensal por pessoa na atividade, e tem um custo operacional próximo a $50 \%$ comparado a receita total.

É possível ainda classificar as propriedades analisadas, de acordo com critérios de Souza (2015), e Canabarro (2015) em: Rudimentar; Em transição inicial; Em transição avançada; Especializado.

Os resultados econômicos das propriedades foram diretamente afetados pela alimentação animal. Esse fato corrobora com o atual modelo de produção proposto pela Epagri

DRd - Desenvolvimento Regional em debate (ISSNe 2237-9029) 
de que para aumentar a geração de renda por área, devemos utilizar e manejar bem pastagens de alto potencial produtivo.

A região do Planalto Norte Catarinense possui como diferencial as áreas de caívas. Essas áreas são sistemas silvipastoris tradicionais, mas que apresentam baixa produtividade animal, pela ausência de manejo (HANISCH et al., 2016). No entanto, com a utilização de manejo adequado os produtores podem associar essas áreas como áreas de produção de pastagens perenes, principalmente no consórcio entre gramíneas e leguminosas e aumentar a produção na propriedade, mantendo ainda as áreas de Floresta Ombrófila Mista, o que aumentaria a sustentabilidade do sistema, e com investimentos de 10 a $15 \%$ dos custos operacionais em pastagens, é possível manter uma lotação animal de 4 U.A. (SIMÕES, 2009).

As pastagens perenes após o plantio inicial e consequente manutenção, não precisam mais serem plantadas, o que se traduz em menor uso de maquinário; facilidade para implantação do piqueteamento; distribuição de água nos piquetes aos animais; redução dos vazios forrageiros; são altamente produtivas e o preço do quilo de matéria seca é muito baixo. Os pontos negativos das pastagens perenes são a dificuldade de implantação; mudanças no manejo, pois o crescimento varia ao longo do ano, e algumas pastagens não se adaptam bem com a técnica de sobressemeadura com azevém (HAHN et al., 2015).

A Epagri recomenda como pastagens perenes para o P.N.C. a missioneira-gigante (Axonopus catharinensis), hemarthria (Hemarthia altissima cv. Flórida); jiggs (Cynodon dactylon cv. Jiggs); tifton 85 (Cynodon dactylon cv. Tifton 85); capim pioneiro (Pennisetum purpureum Schum. cv. Pioneiro); capim kurumi (Pennisetum purpureum Schum. cv. Kurumi); trevo branco (Trifolium repens L.); e amendoim forrageiro (Arachis pintoi) (CORDOVA et al., 2012). Para maximizar o uso das pastagens é necessário utilizar piqueteamento, respeitar a altura de pastejo, a lotação animal e o tempo de repouso (CORDOVA et al., 2012). A adubação recomendada por um profissional habilitado através da análise de solo permite a manutenção das pastagens perenes por tempo indeterminado e aumento da lotação animal $(\mathrm{kg} / \mathrm{peso}$ vivo/área), e aumentar a quantidade de nutrientes das pastagens, que favorece a nutrição (SANTOS et al., 2008).

É necessário instalar um sistema hídrico nos piquetes para os animais beberem água. O comportamento das vacas em lactação mostra que elas não gostam de se locomover, principalmente com calor, por isso, ter água disponível de qualidade e próximo aos animais é fundamental para uma boa produção de leite (SIGNORETTI, 2011).

Como recomendação para o rebanho, é preciso utilizar genética que apresente uma boa produtividade animal com um alto teor de sólidos, somado a animais que utilizam bem a pastagem, devido às exigências que a indústria tem apresentado (KNOB, 2015).

Atualmente, a genética que atende a essas demandas para a produção com base na alimentação em pastagens, é oriunda da Nova Zelândia (MILKPOINT, 2011).

Outro ponto importante é a porcentagem de vacas no rebanho, já que rebanhos com muitos animais em crescimento aumentam a geração de custos. Cada propriedade é única, mas de maneira geral, com os resultados encontrados nesse trabalho sobre a dimensão 01 da PCA é possível atingir altos índices de produtividade e lotação animal, que são fundamentais para uma alta geração de renda por área.

DRd - Desenvolvimento Regional em debate (ISSNe 2237-9029) 
Para atingir bons índices financeiros, precisamos cuidar com os custos de produção conforme dimensão 02 .

Os gastos com ração são responsáveis por quase $50 \%$ dos custos operacionais. Assim, precisamos de estratégias para utilizar de forma racional a ração nas propriedades rurais.

Sincronizar parte dos partos do rebanho com a oferta de pastagem de alta qualidade (na região do P.N.C., a melhor oferta de pastagem em qualidade é no inverno e primavera) e o melhor preço pago pela indústria gera um círculo virtuoso financeiramente (MUHLBACH, 2012; CONSELEITE-SC, 2019).

A oferta de ração que cada animal em lactação deve receber tem de levar em consideração as exigências nutricionais, a alimentação disponível, a condição corporal do animal e a produção diária de leite (SALMAN, 2011). Para isso, devemos realizar a medição da produção de leite por animal a cada 30 dias (EMBRAPA, 2003).

As técnicas de manejo descritas neste trabalho são de baixo custo e eficientes para aumentar os índices produtivos e resultados econômicos da atividade leiteira. É necessário que essas informações cheguem até as propriedades rurais, e que os produtores se conscientizem sobre as mudanças necessárias, pois, serão os maiores beneficiados.

\section{CONCLUSÃO}

Os resultados sugerem que modelos de produção de leite que tem um baixo custo operacional proporcional à receita bruta são mais eficientes para a região do Planalto Norte Catarinense.

A Análise de Componentes Principais permitiu a formação de cinco grupos distintos de sistemas de produção e os das propriedades rurais que tem a atividade leiteira, e os fatores econômicos conseguiram explicar satisfatoriamente as diferenças entre os agrupamentos das propriedades rurais.

Foi possível observar que existe um grupo de risco dentro da atividade leiteira, que tem grande probabilidade de abandono da atividade ou da propriedade rural, que é o grupo C. É fundamental que essas propriedades sejam replanejadas e recebam um acompanhamento técnico prioritário para o desenvolvimento da atividade leiteira.

O grupo A confirmou a evolução de eficiência na atividade leiteira na região do Planalto Norte Catarinense por meio da geração de renda por área com menor custo operacional.

Os resultados desse trabalho apontam para a afirmação de que para uma maior lucratividade, é preciso gerir bem a lotação animal, a produtividade animal e os custos operacionais. 


\section{REFERÊNCIAS}

BOCKSTALLER, C. et al. Agri-environmental indicators to assess cropping and farming systems. A review. Agron Sustain Dev., v. 28, p. 139- 149, 2008. Doi:

10.1051/agro:2007052

CALKER, K. J. V. et al. Identifying and ranking attributes that determine sustainability in Dutch dairy farming. Agriculture and Human Values, v. 22, p. 53-63, 2005.

CANABARRO, L. O. Tipologia de unidades produtoras de leite no Planalto Norte Catarinense. 2015. 121 f. Dissertação (Mestrado) - Universidade Federal de Santa Catarina, Florianópolis, 2015.

CONSELEITE. Preços de referência - SC. Disponível em: $<$ http://conseleite.com.br/precoreferencia/index/estado/sc/ano/2018/> . Acesso em: 10 fev. 2019.

CORDOVA, U. A. (Org). Produção de leite à base de pasto em Santa Catarina. Epagri Departamento Estadual de Marketing e Comunicação - DEMC, 2012.

DERESZ, F. et al. Produção de leite de vacas Holandês x Zebu em pastagens de gramíneas tropicais manejadas sob pastejo rotativo. Circular Técnica, n. 90, Embrapa Gado de Leite, Juiz de Fora, dez. 2006. Disponível em:

$<$ https://docs.ufpr.br/ freitasjaf/artigos/prodleitepastagem.pdf $>$. Acesso em: 05 out. 2018.

DIAS, A. P. O uso de critérios quali-quantitativos de alimentação e práticas de ordenha na tipologia de sistemas de produção leiteira. 2018. 62 f. Dissertação (Mestrado) Universidade Federal do Rio Grande do Sul, Porto Alegre, 2018.

EMBRAPA. Sistema de produção de leite (Zona da Mata Atlântica). 2003. Disponível em: <https://sistemasdeproducao.cnptia.embrapa.br/FontesHTML/Leite/

LeiteZonadaMataAtlantica/alimentacao3.html>. Acesso em 10 fev. 2019.

EPAGRI/CEPA. Síntese anual da agricultura 2016-2017. Disponível em:

$<$ http://docweb.epagri.sc.gov.br/website cepa/publicacoes/Sintese-Anual-da-AgriculturaSC 2016 17.pdf $>$. Acessado em: 06 set. 2018.

FERREIRA, L. R. S. Análise da eficiência econômico-financeira em um sistema de produção de leite. 2016. 55 f. Dissertação (Mestrado) - Universidade Federal da Grande Dourados, Dourados, 2016.

FOOD AND AGRICULTURE ORGANIZATION OF THE UNITED NATIONS (FAO)/Epagri. Plataforma de boas práticas para o desenvolvimento sustentável. Disponível em: < http://www.boaspraticas.org.br/index.php/pt/areastematicas/agricultura/730-leiteepagri $>$. Acesso em: 21 nov. 2018.

GONÇALVES, L. C., BORGES, I., FERREIRA, P. D. Alimentação de gado leiteiro. Belo Horizonte: FEPMVZ, 2009. 
HAHN, L. et al. Gramíneas Forrageiras anuais de inverno em cultivo estreme e em sobressemeadura em tifton 85. ENCICLOPÉDIA BIOSFERA, Centro Científico Conhecer Goiânia, v. 11 n. 21; p. 2015. Disponível em: $<$ http://www.conhecer.org.br/enciclop/2015b/ agrarias/gramineas\%20forrageiras.pdf $>$. Acesso em: 10 fev. 2019.

HANISCH, A. L. et al. Plano territorial de desenvolvimento rural sustentável do planalto norte catarinense, versão preliminar. 2006. Disponível em:

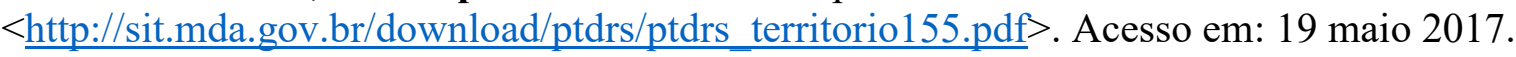

et al. Estrutura e composição florística de cinco áreas de caíva no Planalto Norte de Santa Catarina. Pesquisa Florestal Brasileira, Colombo, v. 30, n. 64, p. 303-310, nov./dez. 2010.

et al. Melhoria da produção animal em áreas de caíva e sua contribuição para a viabilização de corredores ecológicos. DRd - Desenvolvimento Regional em debate, v. 6, n. 2, ed. esp., p. 170-188, jul. 2016.

IBGE. Censo agropecuário. Disponível em: $<\underline{\text { https://censoagro2017.ibge.gov.br/templates/ }}$ censo_agro/resultadosagro/index.html>. Acesso em: 06 set. 2018.

KNOB, D. A. Crescimento, desempenho produtivo e reprodutivo de vacas Holandês comparadas às mestiças Holandês x Simental. 2015. 100 f. Dissertação (Mestrado em Ciência Animal) - Universidade do Estado de Santa Catarina, Lages, 2015.

LEBACQ, T.; BARET, P. V.; STILMANT, D. Sustainability indicators for livestock farming. A review. Agron. Sustain. Dev., v. 33, p. 311-327, 2013.

MARTHA JÚNIOR, G.B.; ALVES, E.; CONTINI, E. Dimensão econômica de sistemas de integração lavoura-pecuária. Pesquisa Agropecuária Brasileira, Brasília, v. 46, n. 10, p. 1117-1126, out. 2011. Disponível em: < http://seer.sct.embrapa.br/index.php/pab/article/ view/10446/6620>. Acesso em: 10 fev. 2019.

MAYER, A. R. Análise multivariada para características de desempenho, carne e carcaça de uma população multirracial Charolês - Nelore. Tese (Doutorado em Zootecnia) Universidade Federal de Santa Maria, 2017.

MILKPOINT. As vantagens da genética da Nova Zelândia. 2011. Disponível em: $<$ https://www.milkpoint.com.br/empresas/novidades-parceiros/as-vantagens-da-genetica-danova-zelandia-73702n.aspx >. Acesso em: 10 fev. 2019.

MUHLBACH. P. R. F. Por que a qualidade da forrageira é fundamental na dieta da vaca leiteira? 2012. Disponível em: $<$ https://pt.engormix.com/pecuaria-leite/artigos/forrageiradieta-vaca-leiteira-t37406.htm>. Acesso em: 10 fev. 2019.

NOVAES, R. C. R. et al. (Orgs). Política Nacional de Juventude: diretrizes e perspectivas. São Paulo, Conselho Nacional da Juventude; Fundação Friedrich Ebert, 2006. Disponível em: $<$ http://bibjuventude.ibict.br/jspui//handle/192/51>. Acesso em: 04 jun. 2019. 
R CORE TEAM. R: A language and environment for statistical computing. $\mathbf{R}$ Foundation for Statistical Computing, Vienna, Austria. 2018. Disponível em: $<$ http://www.R-project.org $>$.

REGAZZI, A. J. Análise multivariada: notas de aula. Viçosa, MG: Universidade Federal de Viçosa, 2002.

SALMAN, A. K. D. Manual prático para formulação de ração para vacas leiteiras. Porto Velho, RO: Embrapa Rondônia, 2011. Disponível em:

$<$ https://ainfo.cnptia.embrapa.br/digital/bitstream/item/66779/1/doc145-vacasleiteiras-1.pdf $>$. Acesso em: 10 fev. 2019.

SANTOS, D. T. et al. Eficiência bioeconômica da adubação de pastagem natural no sul do Brasil. Ciência rural, Santa Maria, v. 38, n. 2, p. 437-444, mar./abr. 2008.

SIGNORETTI, R. D. A importância da água no manejo alimentar de vacas leiteiras. 2011. Disponível em: < importancia-da-agua-no-manejo-alimentar-de-vacas-leiteiras.htm>. Acesso em: 10 fev. 2019.

SILVA, J. C. A importância da certificação de propriedades rurais como livres para brucelose e tuberculose bovina e bubalina para a cadeia produtiva do leite no planalto norte catarinense. Trabalho de Conclusão de Curso (Graduação) - Instituto Federal de Santa Catarina, Campus Canoinhas. Canoinhas, 2017.

SIMÕES, A. R. P. et al. Avaliação econômica de três diferentes sistemas de produção de leite na região do Alto Pantanal Sul-mato-grossense. Agrarian, v. 2, n. 5, p. 153-167, jul./set. 2009.

SOUZA, S. S. P. V. Diagnóstico de unidades produtoras de leite no planalto norte catarinense: o caso da sisclafplan. 2015. 115 f. Dissertação (Mestrado) - Universidade Federal de Santa Catarina, Florianópolis, 2015.

SUDOSKI, W. Programa Planorte Leite no contexto do desenvolvimento regional: a busca de um diferencial. DRd - Desenvolvimento Regional em debate, Canoinhas, v. 6, n. 2, ed. esp., p. 34-50, jul. 2016.

TABACHNICK, B.; FIDELL, L. Using multivariate analysis. Needham Heights: Allyn \& Bacon, 2007.

VILELA, D. et al. (Ed). O agronegocio do leite e políticas públicas para o seu desenvolvimento sustentável. Juiz de Fora: Embrapa Gado de Leite, 2002.

Artigo recebido em: 06/03/2019

Artigo aprovado em: 17/06/2019

Artigo publicado em: 19/06/2019 